\title{
Oxidative stress and antioxidant status in dairy cows during prepartal and postpartal periods
}

\author{
Jana Konvičná1, Mária Vargová1, Iveta Paulíková1, Gabriel Kováčํ, Zuzana Kostecká \\ University of Veterinary Medicine and Pharmacy, ${ }^{1}$ Clinic of Ruminants, ${ }^{2}$ Department of Chemistry, \\ Biochemistry and Biophysics, Košice, Slovak Republic
}

Received October 1, 2014

Accepted January 14, 2015

\begin{abstract}
The aim of the present study was to evaluate the indicators of oxidative stress (malondialdehyde [MDA] ) and antioxidant status (ferric reducing ability of plasma [FRAP]; superoxide dismutase [SOD]; glutathione peroxidase [GSH-Px]; selenium [Se]; vitamin E) in dairy cows of the Slovak Pied cattle from 3 weeks before parturition to 9 weeks after parturition. The mean MDA concentration was significantly $(P<0.001)$ higher in the cows 1 week after calving compared to the cows 3,6 , and 9 weeks after calving. The lowest mean FRAP value was found in the cows 3 weeks after parturition. The SOD activities were increased during the whole monitored time (ANOVA, $P<0.001)$. A significant $(P<0.05)$ decrease of GSH-Px activities was recorded in the cows 1 week after calving compared to the weeks 6 and 9 after calving. Statistical multiple comparison test showed no significant changes in Se between the examined groups. The lowest mean vitamin $\mathrm{E}$ concentration was found in the first week after parturition. Significantly positive correlations $(P<0.05)$ were recorded between Se and vitamin E $(r=0.897)$, SOD and GSH-Px $(\mathrm{r}=0.903)$, while Se and GSH-Px had no significantly positive correlation $(\mathrm{r}=0.520)$. Significant changes between MDA and indicators of oxidative stress (SOD, GSH-Px, vitamin E) confirm that during parturition and onset of lactation, oxidative stress occurs in dairy cows. Exposure of peripartal cows to oxidative stress may cause an increased incidence of metabolic diseases.
\end{abstract}

Peripartal period, lactation, malondialdehyde, antioxidants, diseases

Oxidative stress plays a key role in the onset or progression of numerous human and animal diseases. Dairy cows undergo this deleterious process mainly during the peripartal period. The period of transition between late pregnancy and early lactation is associated with lipid and protein metabolic changes (Castillo et al. 2006). The energy reduction in the first weeks after parturition results in increased fat mobilization, which is related to the generation of lipid peroxides and reactive oxygen species (ROS). These ROS are normally neutralized by sufficient antioxidant levels of living organisms. Imbalance between the production of ROS and the defence ability of biological systems to scavenge these reactive intermediates causes oxidative stress (Trevisan et al. 2001). This important mediator of cellular macromolecule damage must be continuously eliminated and controlled by antioxidant mechanisms to prevent various diseases occurring shortly after calving. Mastitis, metritis, and incidence of retained placenta are three common diseases linked to a compromised immune system. Many health problems also occur in young animals, such as increased neonatal mortality, decreased sucking reflex, weakness, white muscle disease and higher occurrence of infectious diseases (Sordillo et al. 2007). Adequate trace mineral and vitamin nutrition during the peripartal period is essential for an effective antioxidant defence system. It plays an important role in optimizing the immune responses and in helping the dairy cows to cope with the stress of early lactation (Spears and Weiss 
2008). Direct protection of membrane lipids is provided by vitamin E which breaks the self-propagating chain of oxidative damage to the cell membrane. Deficiency of this antioxidant can cause increasing damage to the structure and function of cells (Sies et al. 1992) and therefore, antioxidant concentrations in animals need to be monitored.

The objective of the present experiment was to study the degree of oxidative stress by evaluating the lipid peroxidation levels (malondialdehyde) and antioxidant status in dairy cows during prepartal and postpartal periods. The activities of main antioxidant enzymes (superoxide dismutase, glutathione peroxidase) and the ferric reducing ability of plasma concentration were determined, together with the concentrations of selenium and vitamin E.

\section{Materials and Methods}

Animals

The study was carried out on 14 dairy cows of the Slovak Pied cattle crossbreeds at a farm situated in the village of Malá Vieska near the town of Košice (Eastern Slovakia). Dairy cows with loose housing varied in age from 3 to 5 years. The mean milk production was 7136.3 litres per the last lactation. The animals were fed twice daily with a total mixed ration (TMR) according to the phase of lactation and milk production (Table 1). The cows had free access to drinking water at all times. A total of 84 blood samples were divided into 6 groups at different stages of ante partum (a.p.) and post partum (p.p.) periods:

$\begin{array}{lllll}\text { Group } 1 & \text { (3 wk a.p.) } & - & \text { dairy cows 3 weeks before parturition } & (\mathrm{n}=14) \\ \text { Group } 2 & \text { (1 wk a.p.) } & - & \text { dairy cows 1 week before parturition } & (\mathrm{n}=14) \\ \text { Group 3 } & \text { (1 wk p.p.) } & - & \text { dairy cows 1 week after parturition } & (\mathrm{n}=14) \\ \text { Group } 4 & \text { (3 wk p.p.) } & - & \text { dairy cows 3 weeks after parturition } & (\mathrm{n}=14) \\ \text { Group 5 } & \text { (6 wk p.p.) } & - & \text { dairy cows 6 weeks after parturition } & (\mathrm{n}=14) \\ \text { Group 6 } & \text { (9wk p.p.) } & - & \text { dairy cows } 9 \text { weeks after parturition } & (\mathrm{n}=14)\end{array}$

Table 1. Components of prepartum and postpartum diets $(\mathrm{kg} / \mathrm{head} / \mathrm{day})$.

\begin{tabular}{lccccc}
\hline & 3 wk, 1wk a.p. & 1wk p.p. & 3 wk p.p. & 6 wk p.p. & 9 wk p.p. \\
\hline Meadow hay & 5.5 & 1.5 & 1.5 & 1.5 & 1.5 \\
R 24 & 0.3 & 0.25 & 0.3 & 0.25 & 0.25 \\
Haylage & 4 & 4 & 6 & 6 & 6 \\
Lucerne silage & 13 & 24 & 22 & 22 & 22 \\
Green fodder & & 25 & 25 & 25 & 2.5 \\
Soybean meal & & 0.8 & 2.5 & 2.5 & 2.5 \\
Rape meal & & 3 & 4 & 0.2 & 0.2 \\
Wheat meal & & 0.2 & 0.2 & 1 & 1 \\
Limestone & & 0.5 & 1 & \\
Flaxseed meal & & & & & 3.5 \\
Maize meal & & & & &
\end{tabular}

R 24 - mineral supplement (104 g Ca, 90 g P, 110 g Na, 40 g Mg, 7000 mg Cu, 3000 mg inorganic Mn, 6000 mg inorganic Zn, $40 \mathrm{mg} \mathrm{Se,} 100 \mathrm{mg} \mathrm{I}, 20 \mathrm{mg} \mathrm{Co,} 1000000 \mathrm{IU}$ vitamin A, 100000 IU vitamin D3, 2000 IU vitamin E)

The experiment was carried out in accordance with established standards for animal care and use as recommended Slovak Veterinary and Food Administration, Chamber of Veterinarians and Ethics Committee of the University of Veterinary Medicine and Pharmacy in Košice, Slovak Republic.

Sampling and analysis

Blood was taken by direct puncture of v. jugularis into plastic tubes with $\mathrm{K}_{2}$ EDTA anticoagulant (to determine FRAP and MDA in blood plasma), into plastic tubes with gel activator (to determine Se and vit. E in blood serum), 
and into plastic tubes with heparin (to determine $\mathrm{Hb}$ and GSH-Px in whole blood, and SOD in haemolyzed red blood cells). The tubes with $\mathrm{K}_{2}$ EDTA anticoagulant and gel activator were centrifuged at $1419 \times g$ at $4{ }^{\circ} \mathrm{C}$ for $20 \mathrm{~min}$. Blood serum and plasma were stored at $-18{ }^{\circ} \mathrm{C}$ until analysed. Aliquots of heparinized blood were prepared and immediately frozen at $-80^{\circ} \mathrm{C}$ until analysis. Haemolyzed red blood cells were prepared immediately after blood collection, following the manufacturer's RANSOD kit (Randox, UK) instructions, and stored at -80 ${ }^{\circ} \mathrm{C}$ until analysis. The concentration of haemoglobin in heparinized blood was determined spectrophotometrically within 5 h of collection.

The intensity of lipid peroxidation was performed in $\mathrm{K}_{2}$ EDTA plasma as the concentration of the malondialdehyde (MDA, $\mu \mathrm{mol} / \mathrm{l}$ ) by thiobarbituric acid reaction according to Uchiyama and Mihara (1978) on spectrofluorometer FP-550 (Jasco, Japan). The total plasma antioxidant capacity was determined in K 2 EDTA plasma by the ferric reducing ability of plasma assay (FRAP, $\mu \mathrm{mol} / \mathrm{l}$ ) published by Benzie and Strain (1996) using spectrophotometer Specord 210 Plus (Analytik Jena, Germany). The activity of superoxide dismutase (SOD, $\mu \mathrm{kat} / \mathrm{gHb}$ ) in erythrocyte lysate was measured by the RANSOD kit (Randox, UK) on the automatic biochemical spectrophotometrical analyser Alizé (Lisabio, France). The activity of glutathione peroxidase (GSH-Px, $\mu \mathrm{kat} / \mathrm{gHb}$ ) in heparinized whole blood was assessed by the kinetic method (Paglia and Valentine 1967) using the RANSEL kit (Randox) on the analyser Alizé. In heparinized blood, haemoglobin was determined using Hb kit (Randox) on the Specord 210 Plus to calculate SOD and GSH-Px in $\mu$ kat/gHb units. The samples of blood serum were subjected to the wet mineralisation in the microwave oven MLS-1200 (Milestone, Perkin Elmer, USA) and the concentration of selenium $(\mathrm{Se}, \mu \mathrm{mol} / \mathrm{l})$ was measured using inductively coupled plasma optical emission spectrometry (ICP-OES) on the analyser Optima 2100 DV (Perkin Elmer, USA). Vitamin E (vit. E, $\mu \mathrm{mol} / \mathrm{l}$ ) was evaluated in blood serum on the high performance liquid chromatography system Series 200 (HPLC, Perkin Elmer, USA).

\section{Statistical analysis}

The statistical evaluation of obtained results was performed by assessment of the mean values (x) and standard deviations (SD) in each monitored group of dairy cows. The significance $(P)$ of differences in the mean values of corresponding indicators was carried out by one way analysis of variance (ANOVA). Significance of differences in the means between the groups was evaluated by Tukey's multiple comparison test.

The relationship between the monitored indicators was evaluated by the calculated correlation coefficient and the significance of correlation using linear regression analysis. The statistical analysis was carried out in GraphPad Prism 5.0 Software.

\section{Results}

The experimental results of the indicators of oxidative stress and antioxidant status are presented in Table 2. ANOVA revealed significant differences in the mean values of corresponding variables during the monitored period. The analyses of correlations between monitored indicators are shown in Table 3.

Statistical multiple comparison test revealed significant $(P<0.001)$ differences of the MDA, SOD, GSH-Px, and vit. E means, while the mean FRAP and Se values showed no significance. The highest mean MDA concentration $(0.76 \mu \mathrm{mol} / 1)$ was recorded in the first week after parturition compared to other groups. This value was significantly higher compared to the cows 1 week before and 3, 6, and 9 weeks after parturition $(P<0.05$ and $P<0.001$, respectively). The lowest mean FRAP value $(259 \mu \mathrm{mol} / 1)$ was found in the cows 3 weeks after parturition, but the differences of mean concentrations between examined groups were no significant. The mean SOD activities gradually increased (51.03-65.87 $\mu \mathrm{kat} / \mathrm{gHb})$ during the whole monitored time. A significant $(P<0.05)$ decrease of GSH-Px activities was recorded in the cows in the first week after calving compared to the cows 6 and 9 weeks after calving. Lower Se means $(0.94-1.13 \mu \mathrm{mol} / \mathrm{l})$ were recorded during the whole peripartal period compared to the cows in week 6 after calving $(1.45 \mu \mathrm{mol} / \mathrm{l})$. Significantly the lowest vit. E mean $(2.45 \mu \mathrm{mol} / \mathrm{l})$ was determined in the cows 1 week after parturition compared to the cows 6 and 9 weeks after calving $(P<0.01$ and $P<0.001$, respectively).

By evaluating the correlation between the monitored indicators of oxidative stress and antioxidant status, significantly $(P<0.05)$ positive correlations were recorded between Se and vit. E $(r=0.897)$, SOD and GSH-Px $(r=0.903)$, while Se and GSH-Px had no significantly positive correlation $(\mathrm{r}=0.520)$. Significantly negative correlation was 
Table 2. Indicators of oxidative stress and antioxidant status of dairy cows from 3 weeks (wk) before parturition to 9 weeks after parturition $(\mathrm{x} \pm \mathrm{SD})$.

\begin{tabular}{|c|c|c|c|c|c|c|c|}
\hline \multirow{2}{*}{\multicolumn{2}{|c|}{$\begin{array}{l}\text { Group } \\
\text { of dairy cows }\end{array}$}} & \multicolumn{6}{|c|}{ Indicator } \\
\hline & & $\begin{array}{c}\text { MDA } \\
\mu \mathrm{mol} / 1\end{array}$ & $\begin{array}{l}\text { FRAP } \\
\mu \mathrm{mol} / 1\end{array}$ & $\begin{array}{c}\text { SOD } \\
\mu \mathrm{kat} / \mathrm{gHb}\end{array}$ & $\begin{array}{c}\text { GSH-Px } \\
\mu \mathrm{kat} / \mathrm{gHb}\end{array}$ & $\begin{array}{c}\mathrm{Se} \\
\mu \mathrm{mol} / 1\end{array}$ & $\begin{array}{c}\text { vit. E } \\
\mu \mathrm{mol} / 1\end{array}$ \\
\hline \multicolumn{8}{|l|}{1} \\
\hline 3 wk a.p. & $\begin{array}{c}\mathrm{x} \\
\mathrm{SD}\end{array}$ & $\begin{array}{l}0.57^{\mathrm{a}} \\
0.08\end{array}$ & $\begin{array}{r}278.6 \\
32.22\end{array}$ & $\begin{array}{c}51.03^{\mathrm{a}, \mathrm{A}, \mathrm{B}} \\
6.78\end{array}$ & $\begin{array}{l}6.73^{\mathrm{A}, \mathrm{B}, \mathrm{C}} \\
0.57\end{array}$ & $\begin{array}{l}1.02 \\
0.49\end{array}$ & $\begin{array}{l}2.97^{\mathrm{a}} \\
0.75\end{array}$ \\
\hline \multicolumn{8}{|l|}{2} \\
\hline 1 wk a.p. & $\begin{array}{c}x \\
\text { SD }\end{array}$ & $\begin{array}{l}0.54^{\mathrm{A}, \alpha} \\
0.13^{2}\end{array}$ & $\begin{array}{r}272.2 \\
28.84\end{array}$ & $\begin{array}{c}54.63^{\mathrm{C}, \alpha} \\
8.50\end{array}$ & $\begin{array}{l}7.14 \\
0.62\end{array}$ & $\begin{array}{l}0.94 \\
0.43\end{array}$ & $\begin{array}{l}2.53^{\mathrm{b}, \mathrm{A}} \\
1.12^{2}\end{array}$ \\
\hline \multicolumn{8}{|l|}{3} \\
\hline 1 wk p.p. & $\begin{array}{c}x \\
\text { SD }\end{array}$ & $\begin{array}{l}0.76^{a, b, c, d} \\
0.21\end{array}$ & $\begin{array}{r}270.3 \\
16.14\end{array}$ & $\begin{array}{r}59.22 \\
6.71\end{array}$ & $\begin{array}{l}6.97^{\alpha, \beta} \\
0.41^{2}\end{array}$ & $\begin{array}{l}1.11 \\
0.64\end{array}$ & $\begin{array}{l}2.45^{\mathrm{c}, \mathrm{B}} \\
0.56\end{array}$ \\
\hline \multicolumn{8}{|l|}{4} \\
\hline 3 wk p.p. & $\begin{array}{c}\mathrm{x} \\
\mathrm{SD}\end{array}$ & $\begin{array}{l}0.45^{\mathrm{b}} \\
0.16\end{array}$ & $\begin{array}{r}259.0 \\
31.02\end{array}$ & $\begin{array}{c}62.43^{\mathrm{A}} \\
8.60\end{array}$ & $\begin{array}{l}7.48^{\mathrm{A}} \\
0.48\end{array}$ & $\begin{array}{l}1.03 \\
0.61\end{array}$ & $\begin{array}{l}2.95^{\mathrm{d}} \\
1.18^{-1}\end{array}$ \\
\hline \multicolumn{8}{|l|}{5} \\
\hline 6 wk p.p. & $\begin{array}{c}\mathrm{x} \\
\mathrm{SD}\end{array}$ & $\begin{array}{l}0.40^{\mathrm{c}} \\
0.24^{-}\end{array}$ & $\begin{array}{r}289.1 \\
47.82\end{array}$ & $\begin{array}{c}63.42^{\mathrm{B}, \alpha} \\
5.48\end{array}$ & $\begin{array}{l}7.56^{\mathrm{B}, \alpha} \\
0.41\end{array}$ & $\begin{array}{l}1.13 \\
0.63\end{array}$ & $\begin{array}{l}4.34^{\mathrm{A}, \mathrm{B}} \\
1.57\end{array}$ \\
\hline \multicolumn{8}{|l|}{6} \\
\hline 9 wk p.p. & $\begin{array}{c}\mathrm{x} \\
\mathrm{SD}\end{array}$ & $\begin{array}{l}0.27^{\mathrm{a}, \mathrm{A}} \\
0.17^{2}\end{array}$ & $\begin{array}{r}291.0 \\
27.22\end{array}$ & $\begin{array}{l}65.87^{\mathrm{a}, \mathrm{C}} \\
10.21^{1}\end{array}$ & $\begin{array}{l}7.56^{\mathrm{C}, \beta} \\
0.63\end{array}$ & $\begin{array}{l}1.45 \\
0.34\end{array}$ & $\begin{array}{l}5.77^{\mathrm{a}, \mathrm{b}, \mathrm{c}, \mathrm{d}} \\
2.34^{4}\end{array}$ \\
\hline ANOVA & $P$ & $<0.001$ & ns & $<0.001$ & $<0.001$ & $\mathrm{~ns}$ & $<0.001$ \\
\hline
\end{tabular}

The same indices in a column mean significance of differences in the mean values between the groups: $\alpha, \beta-P<0.05 ; \mathrm{A}, \mathrm{B}, \mathrm{C}-P<0.01 ; \mathrm{a}, \mathrm{b}, \mathrm{c}, \mathrm{d}-P<0.001 ; \mathrm{x}$ - arithmetic mean; SD - standard deviation; a.p. - ante partum; p.p. - post partum; MDA - malondialdehyde; FRAP - ferric reducing ability of plasma; SOD superoxide dismutase; GSH-Px - glutathione peroxidase; Se - selenium; vit. E - vitamin E

Table 3. Correlation coefficients ( $\mathrm{r}$ ) between monitored indicators of oxidative stress and the antioxidant status $(\mathrm{n}=84)$.

\begin{tabular}{lcccccc}
\hline & MDA & FRAP & SOD & GSH-Px & Se & vit. E \\
\hline MDA & -0.539 & -0.650 & -0.789 & -0.641 & $-0.878^{\text {a }}$ & \\
FRAP & -0.539 & & 0.278 & 0.263 & 0.652 & 0.794 \\
SOD & -0.650 & 0.278 & & $0.903^{\text {a }}$ & 0.716 & 0.695 \\
GSH-Px & -0.789 & 0.263 & $0.903^{\text {a }}$ & & 0.520 & 0.669 \\
Se & -0.641 & 0.652 & 0.716 & 0.520 & & $0.897^{\text {a }}$ \\
vit. E & $-0.878^{\text {a }}$ & 0.794 & 0.695 & 0.669 & $0.897^{\text {a }}$ & \\
\hline
\end{tabular}

Significance of correlations: $\mathrm{a}-P<0.05$

MDA - malondialdehyde; FRAP - ferric reducing ability of plasma; SOD - superoxide dismutase; GSH-Px glutathione peroxidase; Se - selenium; vit. E - vitamin E

found between MDA and vit. $\mathrm{E}(\mathrm{r}=-0.879 ; P<0.05)$, and no significant correlations were determined between other determining indicators. 


\section{Discussion}

Pregnancy in dairy cows induces oxidative stress that can be a significant underlying factor leading to dysfunctional host immune and inflammatory responses that can increase the incidence and severity of infectious diseases (Sordillo 2013). The peripartal period is one of the most stressful periods in the life of dairy cows. Dairy cows go through dramatic physiological changes to prepare themselves for the onset of lactation and the climb to peak milk production. In the peripartal cows, tissues consume more oxygen through normal cellular respiration during times of increased metabolic demand in order to provide the energy needed for the onset of lactation. This increase in metabolic activity results in enhanced accumulation of ROS and depletion of important antioxidant defences around the time of calving (Gitto et al. 2002).

Lipid peroxidation is one of the important consequences of oxidative stress. The intensity of this process can be evaluated by measurement of plasma concentrations of malondialdehyde, as a product of oxidative lipid destruction using thiobarbituric acid reactive substances test. Malondialdehyde readily reacts with thiobarbituric acid producing a red pigment that can be measured spectrofluorometrically and the increased MDA concentrations after calving indicate imbalance between oxidants and antioxidants (Castillo et al. 2005; Bouwstra et al. 2010). In the present study, the highest MDA production of dairy cows was determined in the first week after parturition. Similarly to our results, many authors have also recorded a tendency to transient increase of lipid peroxidation in dairy cows in the same period after calving (Mudron and Konvicna 2006; Saleh et al. 2007; Sharma et al. 2011). This change is typical for this period, and increased intake and higher levels of nutritive antioxidants can efficiently decrease the level of lipid peroxidation (Brzezinska-Slebodzinska et al. 1993).

Determination of the ferric reducing ability of plasma concentration provides basic information on the antioxidant status of animals. The total FRAP contributes to individual plasma antioxidants (uric acid, ascorbic acid, vitamin E, bilirubin, albumin, and others). Plasma concentrations of these antioxidants depend on both dietary intake and the synthetic capacity of specific organs, in particular the liver (Benzie and Strain 1996). In our study, the highest mean FRAP was found in the cows 9 weeks after calving. These cows also had the highest mean vit. E, which could contribute to this highest plasma antioxidant activity. A decrease of the mean FRAP was determined one week before calving, and this decrease was recorded until week 3 after parturition. Similarly, Castillo et al. (2005) observed that the obtained mean FRAP value $(247 \mu \mathrm{mol} / \mathrm{l})$ one week after calving gradually decreased during the monitored period. In week 6 after parturition, the lowest mean FRAP value (154 $\mu \mathrm{mol} / \mathrm{l})$ was determined compared to the other groups. Our findings of MDA and FRAP changes with no significantly negative correlation coefficient $(r=-0.539)$ confirmed increased oxidative stress and depletion of antioxidant activity which are typical for this period.

At calving, SOD and GSH-Px enzymes represent the major antioxidant defence components in protecting the cells against increased ROS. Superoxide dismutase catalyses the dismutation of superoxide radical to hydrogen peroxide which is further metabolised to water by GSH-Px enzyme. The higher erythrocyte SOD activity on the day of parturition indicates higher oxidative stress and lower antioxidant status (Bernabucci et al. 2005). During our experiment, the SOD activities were gradually elevated, which was probably caused by a response of the organism to higher superoxide generation, especially after calving. Although the SOD activity increases after calving in dairy cows (Gaál et al. 2006), several recent studies have shown that the antioxidant capacity in peripartal dairy cows is insufficient to counteract the increase in ROS supply (Bernabucci et al. 2005; Castillo et al. 2005). In our study, reduction in GSH-Px activity one week after calving 
could be supported as increasing postpartal oxidative stress. Similar data were obtained by Festilă et al. (2012) who recorded a decrease of mean blood GSH-Px in dairy cows 0-7 days after parturition as a loss of homeostatic control in the postpartal period.

The antioxidant GSH-Px protective system depends on the body selenium concentration, which is required for maintenance of biochemical-physiological functions, such as biological antioxidant, immune function, reproduction, and thyroid hormone metabolism (Surai 2006). The Se status is most frequently assessed either directly from Se concentrations, or indirectly from GSH-Px activity assessment (Pavlata et al. 2001; 2002). Selenium is a very important essential trace element for proper intrauterine and postnatal development of calves. Selenium saturation in newborn kids fed on mother's milk depends on Se concentrations in the mother's body. Although Se passes both placental and mammary barriers, placental transfer is more effective than the transport of Se into milk (Pavlata et al. 2003). These facts may explain our lower Se concentration and GSH-Px activity of means in dry cows compared to the cows at different stages of lactation (Table 2). Similar results were reported by Pilarczyk et al. (2012) that can be attributed to the Se placental transfer. According to Grace (1997), who showed that $0.52-1.00 \mu \mathrm{mol} / \mathrm{l}$ serum Se concentration is marginal level and $>1.00 \mu \mathrm{mol} / 1 \mathrm{Se}$ is considered optimum level, our determined mean Se values $(0.94-1.45 \mu \mathrm{mol} / \mathrm{l})$ were at marginal and optimum levels. These values confirm sufficient selenium supply of dairy cows in monitored time when lower coefficient of correlation $(\mathrm{r}=0.52)$ was observed between Se and GSH-Px, similarly to Pilarczyk et al. (2012) $(\mathrm{r}=0.46)$.

Dietary antioxidants, notably vitamin $\mathrm{E}$ and $\mathrm{Se}$, are important for their ability to contribute to ROS neutralization, thereby impeding the progression toward inflammation. Vitamin $\mathrm{E}$ neutralizes free radicals by formation of the prooxidant vitamin $\mathrm{E}$ radical, which under normal physiological states will be regenerated to vitamin E by GSH-Px and vitamin C. Interestingly, plasma concentrations of vitamin $\mathrm{E}$ decrease through the transition period and low antioxidant status is associated with disorders in transition cows (LeBlanc et al. 2004). These low concentrations are also associated with increased incidence of fatty liver and displaced abomasums (Mudron et al. 1997). Supplementing vitamin E in the pre partum period improves the antioxidant status, decreases inflammatory cytokine production, the incidence and severity of clinical mastitis. Supplemental vitamin E may improves liver function in transition cows and it is also effective at preventing retained placenta (Bourne et al. 2007). Weiss et al. (1990) found that the plasma vitamin E values were influenced by the stage of lactation. These values were essentially constant from drying off until about 1 week pre partum. Vitamin E concentration then dropped by about $50 \%$ and remained low until 3 to 4 weeks post partum. Plasma concentration continued to increase up to 9 weeks post partum. This profile was similar to our results, when the increase of mean vitamin E values was found from 3 weeks to 9 weeks after calving. Significant correlations $(P<0.05)$ were recorded between vitamin $\mathrm{E}$ and $\mathrm{Se}(\mathrm{r}=0.897)$ and vitamin $\mathrm{E}$ and MDA $(\mathrm{r}=-0.879)$. It seems that the drop of vitamin $\mathrm{E}$ around parturition could be due to decreased feed intake during this period and vitamin E could also be transferred from the blood pool to the colostrum and milk pools.

Relationship between the physiological changes associated with parturition and the loss in the overall antioxidant potential was established in dairy cows (Sordillo et al. 2007). The results of our study indicate the occurrence of significant changes of indicators of oxidative stress and antioxidant status of dairy cows during the peripartal and postpartal periods. Dairy cows seemed to have more oxidative stress and low antioxidant defence capacity just after parturition or during early lactation than cows in advanced pregnancy, which may contribute to the incidence of many metabolic diseases. Therefore regular monitoring of the antioxidant defence and supplementation of antioxidants can help to reduce the incidence of these diseases in the transition cows. 


\section{Acknowledgement}

This work was supported by the Slovak Research and Development Agency under contract No. APVV-0475-10 and by VEGA Scientific Grant No. 1/0592/12 from the Ministry of Education.

\section{References}

Benzie IF, Strain JJ 1996: The ferric reducing ability of plasma (FRAP) as a measure of "antioxidant power": the FRAP assay. Anal Biochem 239: 70-76

Bernabucci U, Ronchi B, Lacetera N, Nardone A 2005: Influence of body condition on relationships between metabolic status and oxidative stress in periparturient dairy cows. J Dairy Sci 88: 2017-2026

Bourne N, Laven R, Wathes DC, Martinez T and McGowan M 2007: A metaanalysis of the effects of vitamin E supplementation on the incidence of retained foetal membranes in dairy cows. Theriogenol 67: 494-501

Bouwstra RJ, Nielen M, Newbold JR, Jansen EH, Jelinek HF, van Werven T 2010: Vitamin E supplementation during the dry period in dairy cattle. Part II: Oxidative stress following vitamin E supplementation may increase clinical mastitis incidence postpartum. J Dairy Sci 93: 5696-5706

Brzezinska-Slebodzinska E, Miller JK, Quigley JD, Moore JR 1993: Antioxidant status of dairy cows supplemented prepartum with vitamin E and selenium E. J Dairy Sci 77: 3087-3095

Castillo C, Hernandez J, Bravo A, Lopez-Alonso M, Pereira V, Benedito JL 2005: Oxidative status during late pregnancy and early lactation in dairy cows. Vet J 169: 286-292

Castillo C, Hernandez J, Valverde I, Pereira V, Sotillo J, Alonso-Lopez, M, Benedito JL 2006: Plasma malondialdehyde (MDA) and total antioxidant status (TAS) during lactation in dairy cows. Res Vet Sci 80: $133-139$

Festilă I, Miresan V, Răducu C, Cocan D, Constantinescu R, Coroian A 2012: Evaluation of oxidative stress in dairy cows through antioxidant enzymes glutathione peroxidase (GPX) and superoxide dismutase (SOD). Bulletin UASVM Anim Sci Biotech 69: 107-110

Gaál T, Ribiczeyne-Szabo P, Stadler K, Jakus J, Reiczigel J, Kover P, Mezes M, Sumeghy L 2006: Free radicals, lipid peroxidation and the antioxidant system in the blood of cows and newborn calves around calving. Comp Biochem Physiol B Biochem Mol Biol 143: 391-396

Gitto E, Reiter RJ, Karbownik M, Tan DX, Gitto P, Barberi S, Barberi I 2002: Causes of oxidative stress in the pre- and perinatal period. Biol Neonate 81: 146-157

Grace ND 1997: Use of biochemical criteria to diagnose trace element deficiencies in sheep and cattle. In: Proceedings of 9th International Conference on Animal Production, Free University of Berlin 11-14.09.1997, Verlag Stuttgart 1997

LeBlanc SJ, Herdt TH, Seymour WM, Duffield TF, Leslie KE 2004: Peripartum serum vitamin E, retinol, and beta-carotene in dairy cattle and their associations with disease. J Dairy Sci 87: 609-619

Mudron P, Konvicna J 2006: Thiobarbituric acid reactive substances and plasma antioxidative capacity in dairy cows at different lactation stages. Dtsch Tierarztl Wochenschr 113: 189-191

Mudron P, Rehage J, Sallmann HP, Mertens M, Scholz H, Kovac G 1997: Plasma and liver alpha-tocopherol in dairy cows with left abomasal displacement and fatty liver. Zentralbl Veterinarmed A 44: 91-97

Paglia DE, Valentine WN 1967: Studies on the quantitative and qualitative characterization of erythrocyte glutathione peroxidase. J Lab Clin Med 70: 158-169

Pavlata L, Illek J, Pechová A, Matějičcek M 2002: Selenium status of cattle in the Czech Republic. Acta Vet Brno 71: $3-8$

Pavlata L, Pechová A, Bečváŕ O, Illek J 2001: Selenium status in cattle at slaughter: analyses of blood, skeletal muscle, and liver. Acta Vet Brno 70: 277-284

Pavlata L, Prasek J, Podhorsky A, Pechova A, Haloun T 2003: Selenium metabolism in cattle: maternal transfer of selenium to newborn calves at different selenium concentrations in dams. Acta Vet Brno 72: 639-646

Pilarczyk B, Jankowiak D, Tomza-Marciniak A, Pilarczyk R, Sablik P, Drozd R, Tylkowska A, Skólmowska M 2012: Selenium concentration and glutathione peroxidase (GSH-Px) activity in serum of cows at different stages of lactation. Biol Trace Elem Res. 147: 91-96

Saleh M, Salam A, Mileegy IMH 2007: Oxidative antioxidant status during transition from late pregnancy to early lactation in native and cross bred cows in the Egyptian oasis. Assiut Vet Med J 53: 113

Sharma N, Singh NK, Singh OP, Pandey V, Verma PK 2011: Oxidative stress and antioxidant status during transition period in dairy cows. Asian-Aust J Anim Sci 24: 479-484

Sies H, Stahl W and Sundquist AR 1992: Antioxidant functions of vitamins: vitamins E and C, beta-carotene and other carotenoids. Ann NY Acad Sci 669: 7-20

Sordillo L 2013: Selenium-dependent regulation of oxidative stress and immunity in periparturient dairy cattle. Vet Med Int 2013: 154045

Sordillo LM, O'Boyle N, Gandy JC, Corl CM, Hamilton E 2007: Shifts in thioredoxin reductase activity and oxidant status in mononuclear cells obtained from transition dairy cattle. J Dairy Sci 90: 1186-1192

Spears JW, Weiss WP 2008: Role of antioxidant and trace elements in health and immunity of dairy cows. Vet J 176: 70-76 
Surai PF 2006: Selenium in Ruminant Nutrition. In: Surai PF (Ed.): Selenium in Nutrition and Health. Nottingham University Press, Nottingham, pp. 487-587

Trevisan M, Browne R, Ram M, Muti P, Freundenheim J, Carosella AN, Armstrong D 2001: Correlates of markers of oxidative status in the general population. Am J Epidemiol 154: 348-356

Uchiyama M, Mihara M 1978: Determination of malonaldehyde precursor in tissues by thiobarbituric acid test. Anal Biochem 86: 271-278

Weiss WP, Hogan JS, Smith KL, Hoblet KH 1990: Relationships among selenium, vitamin E, and mammary gland health in commercial dairy herds. J Dairy Sci 73: 381-390 